\title{
Editorial
}

\section{NANOTR9: 9th Nanoscience and Nanotechnology Conference}

The conference series NanoTR is the major conference on nanoscience and nanotechnology in Turkey. It brings together leading scientists and engineers in nanotechnology to exchange information on their latest research progress. An exhibition of the companies working in the related field is also organized as a part of the event. With intensive international participation, NanoTR conference series has spread outside the national border and has become an international event in this field. Among international contributions, a wide interest from the countries around Turkey should be emphasized. 9th in the series was organized by Atatürk University in Erzurum-Turkey on June 24-28, 2013 with more than 900 scientists, researchers, private sector representatives from around the world. Conference program included 6 plenary speakers, 35 invited speakers ( 18 of them were from outside the country), 116 oral presentations, and 340 poster presentations. In addition to 6 plenary sessions, 17 oral and 4 poster sessions created very lively discussion forums covering a vast range of current and emerging sciences from nano-materials, nanoscience, nanofabrication, nanoengineering, nano-electronics, nano-biotechnology, to ethical and social issues of nanoscience and nanotechnology. Also, panel discussions about industrial applications, tutorial sessions have been organized for students, new-comers and company employees.
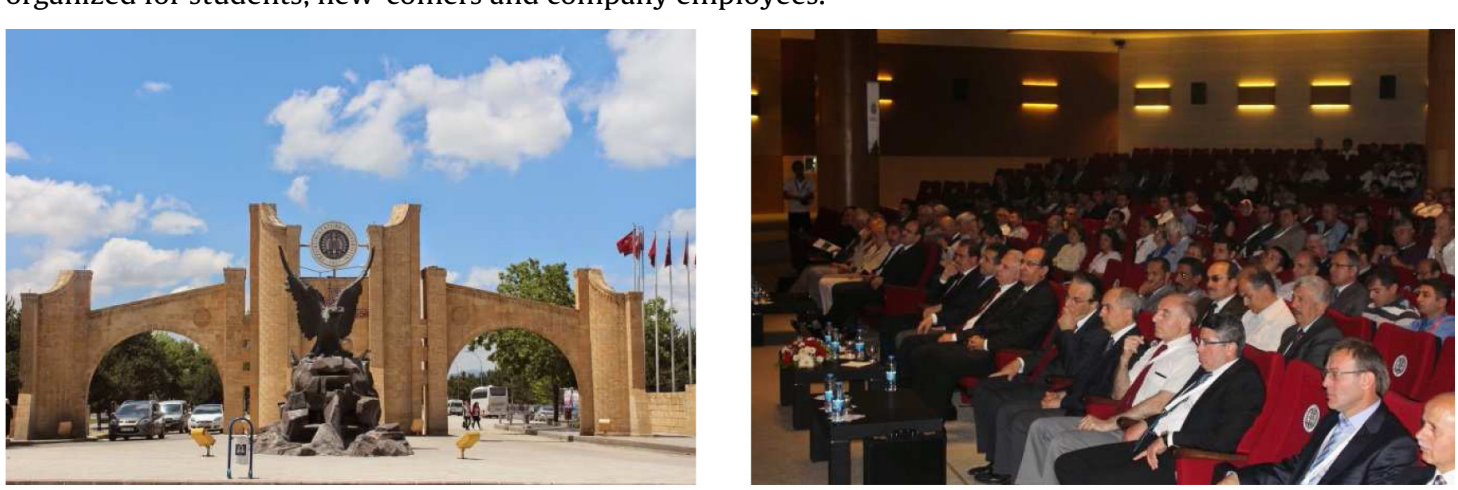

(a) Conference site: Atatürk University, Erzurum and (b) Picture from the main

conference hall

Some of the topics discussed during the conference is listed below:

\footnotetext{
- Nano materials, Nano particles, Nano crystals, Nano transparent materials, Molecular and supra-molecular materials, Nano tubes, Nano rods, Nano composites.

- Nano membranes, Electro-chemical materials.
}

Prof. Dr. Raşit Turan, Middle East Technical University, Ankara, Turkey.

Prof. Dr. Ümit Demir, Atatürk University, Erzurum, Turkey. Prof. Dr. Oğuz Gülseren, Bilkent University, Ankara, Turkey. Prof. Dr. Kalman Varga, Vanderbilt University, Vanderbilt, USA.

Nano medicine, Operated dispersion systems, Regenerative medicine, Diagnosis and Imaging.

- Nanoelectronics, Spintronics, Nano magnetic structures, Organic and hybrid electronics, Nano-optics, Nano-optoelectronics, Nano photonics.

- Graphene.

- Nano fabrication, Nano-lithography.

- Nano-characterization, Nano-imaging, Nanoscopy.

- Nano-mechanics, Nano electro-mechanic systems (NEMS), Nano robotics, Nano tribology, Nano fluids, Nano actuators, Nano sensors.

- Ethics and social attitude, Nano security, environmental effects, and risk evaluation, Regulating configuration, National nanotechnology policies, Intellectual property, Education and educational needs.

We believe and hope that NanoTR series will continue with a growing interest in the future.

Guest Editors for NanoTR9 Special issue: 